\title{
Critical review on the relationship between glaucoma and alzheimer's disease
}

\begin{abstract}
A third of people affected by primary open angle glaucoma (POAG) have normal or even low intraocular pressure (IOP), such as in the case of normotensive glaucoma and low pressure glaucoma. Therefore, high IOP, while remaining the most important risk factor for POAG development, is not the only one. POAG has been recognized to belong to the class of neurodegenerative diseases, such as Alzheimer's (AD) and Parkinson's, and several recent studies have suggested possible links between Alzheimer's and glaucoma both from an epidemiological and a pathogenetic point of view. In fact, several pathogenetic factors are common between the two diseases: the diffuse axonal degeneration of ganglion cells, the presence of specific markers (such as amyloid- $\beta$ ) in the aqueous humor, the activation of caspases and the abnormal processing of amyloid precursor protein in retinal ganglion cells, the reduction of the intracranial pressure of the cerebrospinal fluid, the mutations of the gene that encodes for optineurine. Conflicting data have been reported concerning apolipoprotein E. Finally, numerous publications affirm the utility of molecules traditionally used in the treatment of neurodegenerative diseases (e.g. forskolin, L-carnosine, homotaurine, folic acid, acetylcholinesterase inhibitors, antioxidant vitamins, glatiramer acetate, etc.) also in the treatment of glaucoma. In the present research we analyze the common pathogenetic pathways of Alzheimer's disease and Glaucoma, we discuss the two diseases with respect to their differences and similarities and we speculate about common therapies, based on the similar pathogenetic findings.
\end{abstract}

Keywords: amyloid- $\beta$, alzheimer's disease, glaucoma, neurodegeneration, neuroprotection
Volume I Issue 4 - 2014

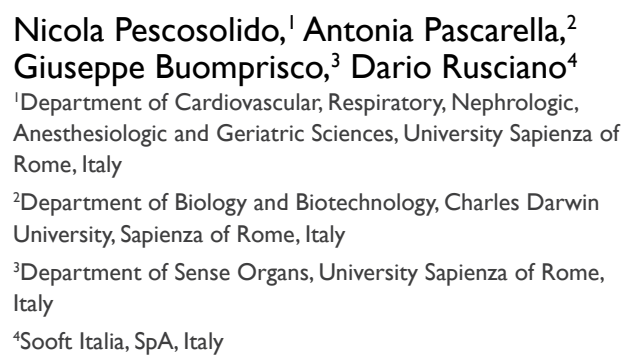

Correspondence: Dario Rusciano, Sooft Italia S.p.A.,Via Salvatore Quasimodo 136, 00 I44, Rome, Italy, Email dario.rusciano@sooft.it

Received: October 15, 2014 | Published: December 6, 2014
Abbreviations: POAG, primary open angle glaucoma; IOP, intra-ocular pressure; APP, amyloid precursor protein, RGCs, retinal ganglion cells; CSF, cerebro-spinal fluid; APOE, apolipoprotein E; $\mathrm{AD}$, alzheimer's disease; EGS, european glaucoma society; RNFL, retinal nerve fiber layer; GON, glaucomatous optic neuropathy; PD, parkinson's disease; NMDA, N-Methyl D-Aspartate; BDNF, brainderived neurotrophic factor; EOFAD, early-onset familial AD; MCI, mild cognitive impairment; PET, positron emission tomography; SPECT, single-photon emission computed tomography; MRN, magnetic resonance neurography; $\mathrm{CT}$, computed tomography; TNF- $\alpha$, tumor necrosis factor $\alpha$; OCT, optical coherence tomography; DKEFS, delis-kaplan executive function system; GDS, geriatric depression scale; GAI, geriatric anxiety inventory; CVLT-IIED, california verbal learning test- second edition; PERG, pattern electroretinogram; NTG, normo-tensive glaucoma; HHcy, hyper-homocysteinemia; AßPP, amyloid- $\beta$ protein precursor; FDA, food and drug administration; ON, optic nerve; OAG, open angle glaucoma; CSI, conformationalselective interference; ER, endoplasmic reticulum; EGR-1, early growth response 1; EGCG, epigallocatechin gallate; ERG, electroretinogram; CAMP, cyclic adenosine monophosphate; $\mathrm{AH}$, aqueous humor; PKA, protein kinase A; ROS, reactive oxygen species

\section{Introduction}

Until recently, POAG and AD had always been described as two distinct pathologies, despite similar pathophysiology and demographic distribution. Both diseases are neurodegenerative, chronic and progressive in nature, with irreversible neuronal cell loss. Furthermore, both POAG and AD disease primarily affect the elderly, with a strongly age-dependent incidence. The progressive debilitating course of both diseases has tremendous implications on an aging population. ${ }^{1}$ For years Glaucoma has been associated with high IOP, ${ }^{2}$ although scientists had accepted this etiology with caution, since it was known that POAG could develop in subjects with normal or even low IOP. In fact, one out of three POAG patients has normotensive or low tension glaucoma. ${ }^{3}$ This observation has led the scientific community to look for other possible causes of this slowly debilitating pathogenesis.

The hallmark of neurodegenerative diseases is the death of specific neuron populations and of those other neurons that are inter-connected and depend for their survival on the inputs from the main population (trans-synaptic degeneration). In Parkinson's disease accumulation of alfa-synuclein ${ }^{4}$ causes the degeneration of dopaminergic neurons of the substantia nigra, in the midbrain, thus leading to the classic symptoms of Parkinson's such as tremor, akinesia, bradykinesia, and stiffness. ${ }^{5}$ In $\mathrm{AD}$ there is a loss of neurons in the cerebral cortex and certain subcortical regions. This loss results in gross atrophy of the affected regions, including degeneration in the temporal lobe and parietal lobe, and parts of the frontal cortex and cingulate gyrus. ${ }^{6}$ Both amyloid plaques and neurofibrillary tangles are clearly visible by microscopy in the brains of those afflicted by AD. ${ }^{7}$ Plaques are dense, mostly insoluble deposits of beta-amyloid peptides and cellular material outside and around neurons. Tangles (neurofibrillary tangles) are aggregates of the microtubule-associated protein tau which has become hyper-phosphorylated and accumulates inside the cells themselves, disrupting the intracellular transport system. Beta amyloid plaques and/or neurofibrillary tangles trigger apoptosis of neuronal cells, thus causing the disease. ${ }^{8}$ 
POAG results from the death, mainly by apoptosis, of RGCs, which in turn causes, by trans-synaptic degeneration, the shrinking of the lateral geniculate nuclei, and finally of the occipital cerebral cortex. ${ }^{9}$ It is not yet clear what initiates the death cycle of RGC; it could be an effect of high IOP, sometimes due to a malfunction of the trabecular meshwork and the lamina cribrosa, and/or also a true neurodegenerative mechanism, triggered by the toxic accumulation of some metabolites. In favor of this hypothesis, some studies have reported that amyloid-beta, a substance found in cerebral tissues of $\mathrm{AD}$ patients, is also implicated in RGC death. ${ }^{10}$ Conversely, other studies have shown a relatively higher occurrence of POAG in $\mathrm{AD}$ patients. ${ }^{11-18}$

\section{Discussion}

\section{Primary open angle glaucoma: more than just high pressure}

Glaucoma, according to the updated definition of the European Glaucoma Society (EGS), is a "chronic optic neuropathy with morphologic alterations of the optic nerve head and RNFL which causes alteration of visual perimetry without any other eye pathology". IOP higher than normal $(>21 \mathrm{mmHg})$ is still considered the main risk factor for POAG development. Several types of Glaucoma are known; these can be divided in primary and secondary. Primary glaucomas have an intrinsic etiology, depending on physiological or anatomical defects of the optic system; secondary glaucomas depend on extrinsic causes, such as drugs (iatrogenic glaucoma, e.g. after intravitreal steroid injection) or traumas. Primary glaucoma can occur with a closed iridocorneal angle (acute closed-angle glaucoma), or with an open angle. The most prevalent form of glaucoma is the primary open angle glaucoma, in which the iridocorneal angle, the main way for the outflow of aqueous humor, is freely accessible, but the draining tissuethe trabecular meshwork-may become less permeable.

There are two main types of POAG: one that occurs with an IOP higher than normal $(>21 \mathrm{mmHg})$ and represents $66 \%$ of the total POAG and the other occurring with an IOP $<21 \mathrm{mmHg}$, which can be normal (normotensive glaucoma) or even lower, than normal (low tension glaucoma). However, also in these latter cases, the main therapy still relies upon a further IOP decrease. Glaucoma is a neurodegenerative disorder caused by RGC apoptosis, due to a variety of complicated mechanisms. According to various theories, factors including elevated IOP and vascular dysregulation ${ }^{19}$ primarily contribute to the initial insult during glaucomatous atrophy in the form of obstruction of axoplasmic flow within RGC axons, alteration in optic nerve microcirculation at the level of lamina and changes in the laminar glial and connective tissues. Deprivation of neurotrophic factors, such as the BDNF, and release of a large number of neurotoxic agents within the retina, including glutamate, nitric oxide and free radicals, are the consequences of the above-mentioned events. Currently, IOP reduction is the only proven clinical therapy available for the treatment of glaucoma. However, clinicians know that signs of progression can be seen in many patients despite well controlled IOP. In addition, glaucomatous optic neuropathy has been observed in patients with 'normal' IOP. Therefore, the pathophysiology of glaucoma and particularly normal tension glaucoma probably goes beyond IOP alone. Studies on low pressure glaucoma have demonstrated that in most patients high intraocular pressure is unrelated to poor visual fields.
Over the past decade, most studies have focused on assessing neuroprotective treatments along with IOP lowering medications in order to prevent ganglion cell death or even reverse the process of cell death. Neuroprotection aims at blocking primary destructive events affecting RGCs or optic nerve fibers, enhancing their survival mechanisms and finally repairing damage occurring during the progressive, secondary stage of the injury. ${ }^{20}$ Direct neuroprotection protects cells against intrinsic mechanisms of cell death and apoptosis, such as an excess of free radicals, glutamate excito-toxicity, or imbalance of cell survival/death factors. Indirect neuroprotection protects the cells from local damaging environmental events such as elevated IOP and low vascular perfusion. ${ }^{21}$ Neuroinflammation has also been associated with POAG ${ }^{22}$ because it appears to be a major contributor to the development of other chronic neurodegenerative diseases beside POAG, such as AD and PD. ${ }^{22}$ Therefore, research in these recent years has been focused on addressing the similarities between the different slow progressing neurodegenerative diseases, to see whether it could be possible to find a common mechanism of neuron cell death that could be counteracted by specific drugs or natural molecules, according to a neuroprotection strategy.

A promising medical approach for glaucoma neuroprotection resided in glutamate antagonists. These molecules are able to protect cell membranes against the hyperactivity of NMDA receptors. In particular memantine, being well-tolerated, has been widely used in $\mathrm{AD}$, and its neuroprotective properties have been demonstrated in an animal model of RGC death. ${ }^{23}$ However, the largest randomized phase III clinical trial concerning the efficacy of memantine for POAG showed no significant benefits. ${ }^{24-26}$ In 2009 Nahagara et al. ${ }^{27}$ demonstrated that neurotrophins (and in particular BDNF) have neuroprotective effects in several (transgenic mice, adult rats and adult primates) animal models of AD. Moreover the use of stem cells bioengineered to over express BDNF has shown to protect RGCs in a rat eye model of hypertension; ${ }^{28}$ on the other hand, Chader $^{29}$ affirms that neurotrophins can only delay cell death, without providing a real cure. Recently researchers have investigated anti-inflammatory agent properties in counteracting neuronal damage. Szekely and Zandi in $2010^{30}$ reviewed several epidemiological studies in order to clarify if non-steroidal anti-inflammatory drugs may be neuro-protective, and found the evidence controversial. A more promising approach is provided by the use of antioxidants, because various degenerative disorders are associated with oxidative stress. In particular, for glaucoma it seems that oxidative stress may induce RGC death through damage of the trabecular meshwork, the optic nerve head and the retina. Among antioxidant molecules, vitamin $\mathrm{C}$, vitamin $\mathrm{E}$ and Ginkgo biloba have been extensively studied. ${ }^{31-33}$

Finally, in 2003 Bachurin et al. ${ }^{34}$ were among the first to propose a role for mitochondria in neuroprotection. In fact, they observed that beta-amyloid protein is able to induce the opening of mitochondrial pores that, in turn, play an important role in neurotoxicity. Three years later Osborne et al. ${ }^{35}$ proposed the hypothesis that RGCs in POAG exist at a low energy state because of low blood perfusion, so that their ability to get rid of the excess of ROS produced by axon mitochondria when they are directly hit by short wavelength radiation is impaired, thus resulting in oxidative stress and finally apoptotic cell death. Such hypothesis has been confirmed in further reports, ${ }^{36-38}$ leading to the suggestion that supplementation with creatine, alpha-lipoic acid, nicotinamide and EGCG could be protective for mitochondria, ${ }^{39,40}$ and useful to treat neurodegenerative pathologies. Therefore, the improvement of neuronal mitochondrial respiration could be a promising approach for neuroprotection. 


\section{Alzheimer's disease and its pathogenesis}

$\mathrm{AD}$ is the most common type of dementia; it has a chronic progression and involves about $5 \%$ of people over 65 years of age. ${ }^{34}$ Currently it affects 26 million people around the world, and it is estimated that in 2050 there will be over 100million of affected individuals. ${ }^{41}$ The risk of contracting the disease, in fact, increases with age: it has been calculated that nowadays about $20 \%$ of the population aged over 85 is affected by AD. However, there are rare cases of people who may have an early onset of the disease before the fourth decade of life (EOFAD: early-onset familial AD).

The course of the disease and its clinical manifestations are highly variable.

Three main stages can be identified:

i. Mild dementia (mean duration 2-4 years) is characterized by progressive amnesia and other cognitive deficits. The person finds it difficult to orient him/herself in space and time, language begins to be compromised, mood becomes more and more depressed and anxious, aggressive manifestations may also occur.

ii. Moderate dementia (mean duration 2-10 years) is characterized by a progressive worsening of symptoms experienced in the previous stage. The subject becomes progressively unable to provide for her/his own needs.

iii. Severe dementia (mean duration 3 years) is the terminal phase of the disease, in which the person is lying in bed and not able to move, to speak, to recognize others, to control physiological stimuli (sphincter control may be lost), or express emotions, to take care of her/his livelihood necessities, therefore needing total and ongoing support.

The disease can also be preceded by a pre-dementia stage, called MCI (Mild Cognitive Impairment), a kind of cognitive decline, frequent in the elderly population, but not necessarily indicative of an incipient dementia. Several conditions are now proven risk factors for $\mathrm{AD}$; among these are diabetes, obesity and hypercholesterolemia. ${ }^{41}$ The diagnosis of $\mathrm{AD}$ is a probabilistic diagnosis that is based, currently, on a series of tests. First level tests can be questionnaires designed to assess the intellective, emotional and functional status of the subject, such as the Mini Mental State Examination (Figure 1). ${ }^{42}$ Second level tests include PET, SPECT, MRN and $\mathrm{CT}^{43}$ (Figure 2).

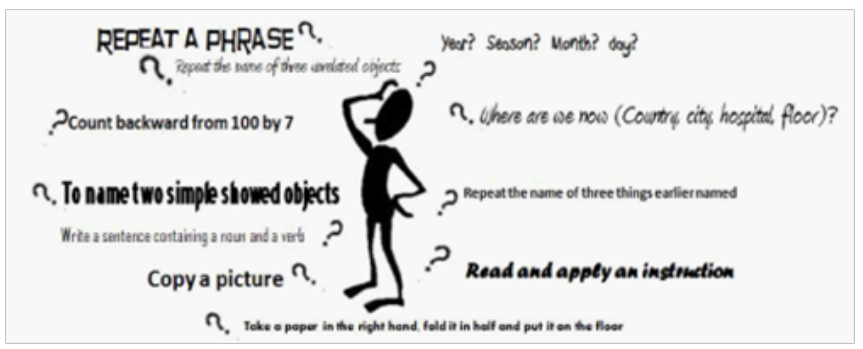

Figure I Mini Mental State Evaluation (MMSE) test is used to assess mental and cognitive status. It is an II-question test that scores for orientation, retention, attention, recall and language. The maximum possible score is 30 , representing high function. A score of 23 or lower is indicative of cognitive impairment.

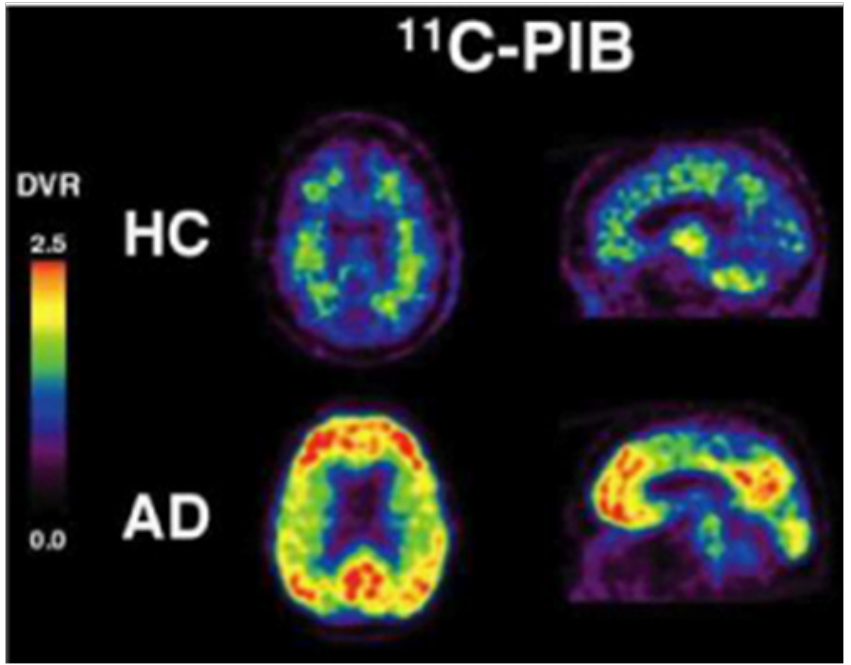

Figure 2 Transaxial and sagittal distribution volume ratio (DVR) of the $A \beta$ ligand" " C-PIB. PET images of a representative healthy control $(\mathrm{HC})$ subject (age: 84, MMSE: 30) and an Alzheimer's disease patient (age: 83, MMSE: 22). Image credit to Dr Victor Villemagne and Associate Professor Chris Rowe, PET Centre, Austin Health, Heidelberg, Australia.

The pathogenesis of the disease ${ }^{44}$ is characterized by progressive neuronal death mainly due to the accumulation in the extracellular space of the $\beta$-amyloid protein (Figure 3), which is produced by the predominant action in these patients of the enzyme $\beta$-secretase on the APP. In healthy subjects the APP is cleaved instead by $\alpha$-secretase, and does not generate the insoluble precursor $\beta$-amyloid (Figure 4). $\beta$-amyloid tends to form insoluble aggregates (amyloid or senile plaques) that are deposited in extracellular spaces (Figure 3 ) and trigger an inflammatory process (production of cytokines, interleukins and TNF- $\alpha$, activation of immune cells etc.) finally leading to neuronal death. Moreover, beside the amyloid plaques, the abnormally phosphorylated tau protein also forms insoluble structures, the neurofibrillary tangles (Figure 5) that are pathognomonic for $\mathrm{AD}$. A third characteristic pathogenetic element in $\mathrm{AD}$ is amyloid angiopathy ${ }^{45}$ a form of angiopathy in which amyloid deposits form in the CNS blood vessel walls ${ }^{46}$ thus increasing the risk of cerebral micro-hemorrhages.

$\mathrm{AD}$ is characterized by the loss of neurons and synapses in the cerebral cortex and certain subcortical regions, leading to degenerative changes in a variety of neurotransmitter systems. These include alterations in the function of the monoaminergic neural systems that release glutamate, norepinephrine, and serotonin as well as other neuropeptide-containing systems. This neuron loss results in gross atrophy of the affected regions, including degeneration in the temporal lobe and parietal lobe, and parts of the frontal cortex and cingulate gyrus. ${ }^{6}$ The destruction of neurons then leads to a progressive, diffuse cerebral atrophy (Figure 6), the total volume of the brain is reduced and the parenchyma is replaced by CSF that expands the ventricle (Figure 7) and may lead to normotensive hydrocephalus. ${ }^{47}$ 


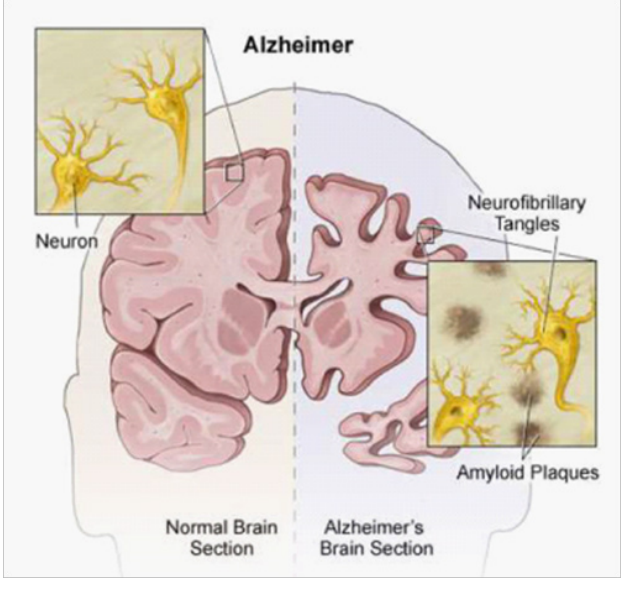

Figure 3 An illustration comparing a normal brain and a brain affected by Alzheimer's disease.Amyloid plaques (abnormal clusters of protein fragments) build up between nerve cells, whereas neurofibrillary tangles made up of Tau protein grow inside neurons. Image credit to: student osteopathic medicine. tumblr.com

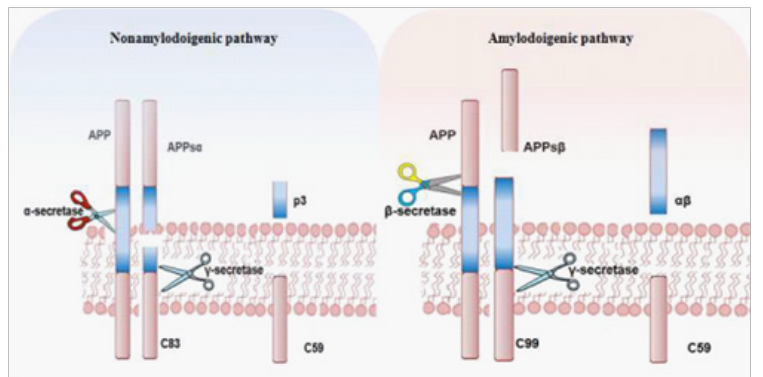

Figure 4 The amyloid precursor protein (APP) is a transmembrane protein that can undergo a series of proteolytic cleavages by secretase enzymes. When it is cleaved by $\alpha$-secretase in the middle of the $\beta$-amyloid domain it is not amyloidogenic. However, when APP is cleaved by $\beta$-and $\gamma$-secretase enzymes, insoluble neurotoxic $A \beta$ peptides are released, which can accumulate in oligomer aggregates.

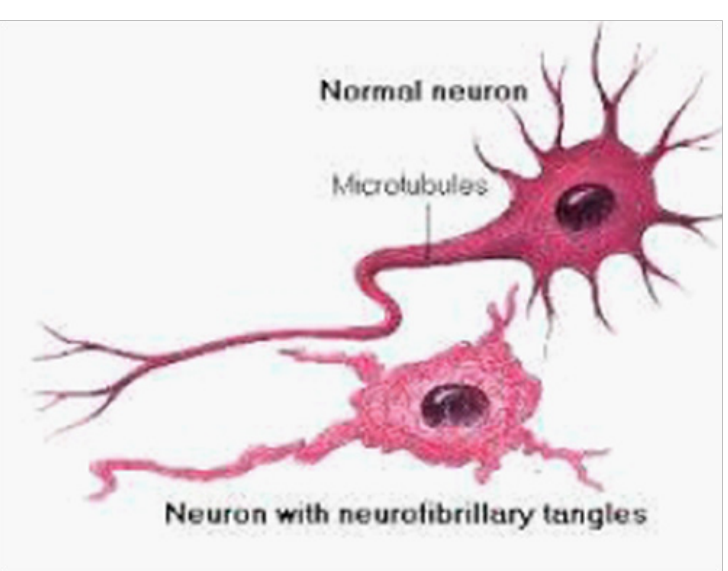

Figure 5 Difference between normal and Alzheimer's neurons. Top: normal neuron without Alzheimer's. Bottom: Deposition of neurofibrillary tangles in brain nerve cells with Alzheimer's disease. Image credit to Nation Institute of aging. Illustrator Lydia Kibiuk

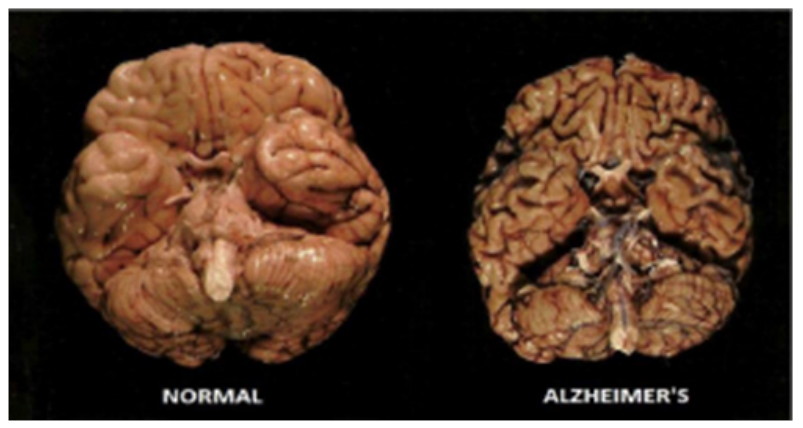

Figure 6 Comparison of a normal human brain and a brain from a patient who died with AD. Image credit to sumitachakraborty.com

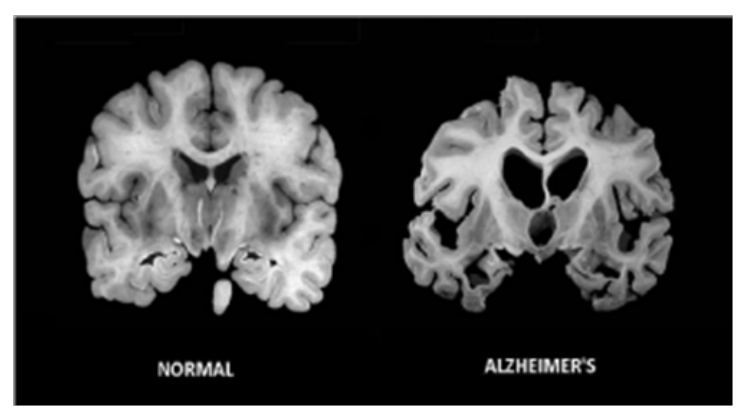

Figure 7 Massive cell loss changes the brain in advanced Alzheimer's disease. Image credit to going gentle into that goodnight.com

\section{Alzheimer' disease and eye pathologies}

Often, eye involvement is an early occurrence in AD..$^{48-50}$ There are reports describing reduction of perimetric indexes, ${ }^{51,52}$ contrast sensitivity, ${ }^{53,54}$ perception of movement ${ }^{55,56}$ and colors. ${ }^{57}$ Previously, all these defects were considered to be due to pathological changes in the cortex. However, the development of modern ocular imaging techniques has shown that pathological changes within the retina could also be found in these patients. ${ }^{58}$ Moreover, since AD is known to be characterized by a dysfunction of the cholinergic system, which also regulates the pupillary diameter, several studies have explored and demonstrated a hypersensitive response of AD patients to both mydriatic (e.g. tropicamide) and miotic (e.g. pilocarpine) drugs. ${ }^{59-67}$ Some have even proposed that this altered response could be pathognomonic of $\mathrm{AD}^{68-71}$ while others have refuted this hypothesis as non-specific. ${ }^{72}$ The crystalline lens also could be involved in $\mathrm{AD}$, and high levels of $\beta$-amyloid were described in lens epithelia of subjects with a particular and rare type of cataract, the anterior subcapsular cataract. ${ }^{73,74}$ Other authors have investigated possible changes in retinal anatomy in patients with $\mathrm{AD}$, reporting an abnormal reduction of retinal thickness (by OCT) ${ }^{75}$ associated with defective blood flow. ${ }^{76}$ This retinal damage appears to be associated with increased amounts of b-amyloid and tau proteins in the vitreous body. ${ }^{77}$ Finally, a reduction in the number of optic nerve fibers, probably due to the toxicity on RGCs of $\beta$-amyloid, has been detected in some studies. ${ }^{78-80}$

Glaucoma and Alzheimer's disease, from epidemiological relationship to common pathogenetic mechanisms

Studies suggesting a possible link between Alzheimer's disease and glaucoma have sought this relationship studying either epidemiological data, or pathogenetic events that occur in both 
conditions (Figure 8). Chandra and colleagues ${ }^{81}$ first described a high frequency of glaucoma occurrence in patients with presenile and senile dementia, after analyzing thousands of death certificates in the United States from 1978 to 1986 . In 2002, Bayer et al. ${ }^{82,83}$ described a series of 49 patients with $\mathrm{AD}, 12$ of which $(24.5 \%)$ presented with diagnostic criteria for glaucoma, having visual field defects with a cup/ disk ratio $>0.8$. This finding was subsequently confirmed and extended in a study with a larger case series: 112 subjects with $\mathrm{AD}, 29$ of them were consistent with the diagnosis of glaucoma; this represented a prevalence of $25.9 \%$ in this group, compared to a prevalence of 2.6$4.7 \%$ in the same age class of the general population. In a control group of 116 subjects living in the same environment, the incidence of glaucoma was $5.2 \%$, not dissimilar from that of the general population. Yochim and colleagues ${ }^{84}$ evaluated 41 patients with glaucoma (age $70 \pm 9.2$ years, $70 \%$ females) with a series of questionnaires (DKEFS, GDS, GAI , CVLT-II ED) to assess their cognitive status; $44 \%$ of the subjects showed an obvious cognitive impairment, and $12.2 \%$ had MCI. PERG is an electrophysiological test that analyzes the electrical response of RGCs, and has been proposed as a test for the diagnosis and follow-up of early POAG alterations. In a retrospective analysis, Nesher and Trick ${ }^{85}$ compared the PERG of 42 patients with glaucoma, 13 patients with $\mathrm{AD}, 58$ patients with diabetes mellitus and 92healthy control subjects and observed a similarity of alterations in the recordings of patients with $\mathrm{AD}$ and glaucoma.

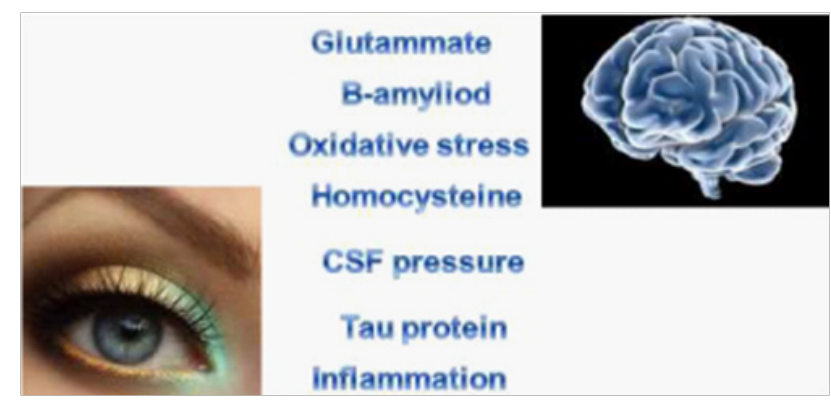

Figure 8 Several studies suggest possible common etiopathogenic factors existing between POAG and Alzheimer's disease.

However, conflicting data have been reported among the different studies carried out to compare glaucoma frequency in normal and AD subjects. Kessing et al. in $2007^{86}$ analyzed the hospital records in Denmark from 1977 to 2001, and measured the average incidence of AD in 11,721 patients with POAG and in other patients with other diseases typical of old age (cataracts, arthritis, etc.), and did not find statistically significant differences. Similarly, Bach-Holm et al. ${ }^{17}$ did not find comorbidity between the two pathologies, and the same was true for a study published in 2012 by Ou et al. ${ }^{18}$ Taken together, all these observations suggest nonetheless the idea of similar pathogenetic mechanisms between $\mathrm{AD}$ and glaucoma, two diseases in which neuronal cell death plays an important role in pathogenesis and prognosis. In fact, Hinton and colleagues ${ }^{87}$ found widespread axonal degeneration of RGCs in the optic nerves of $8 / 10$ patients with AD. Sadun and Bassi further reported that in 10 patients with AD this loss was predominant among the most numerous class of retinal ganglion cells, the $\mathrm{M}$ cells, reporting an observed loss between $30 \%$ and $60 \%{ }^{88}$

The study of Janciauskiene et al. ${ }^{89}$ is interesting, in this context. It demonstrated the presence of specific markers of $\mathrm{AD}$, such as amyloid- $\beta$, in the aqueous humor of patients suffering from glaucoma. Furthermore, it seems that the activation of caspases and the transformation of the abnormal APP, important events that occur in $\mathrm{AD}$, also occur in the RGCs of rats with experimental glaucoma. In 2007 Guo et al..$^{90}$ demonstrated that amyloid- $\beta$ is upregulated in the hippocampus of AD patients and RGCs of a glaucoma rodent model. Moreover, intravitreal injection of amyloid- $\beta$ induces apoptosis in a dose dependent manner. Reducing the level of amyloid- $\beta$ decreases glaucomatous RGC apoptosis in rats. ${ }^{90}$ Other conflicting data concerned the APOE, which is heavily involved in the neuronal degeneration characteristic of $\mathrm{AD}$, but is not yet convincingly associated with glaucoma. The inheritance of a particular polymorphism of the APOE gene, carried by allele 34 , according to some authors, ${ }^{91,92}$ has been shown to be associated not only with a high risk for $\mathrm{AD}$, but also for glaucoma; another paper by Kountouras ${ }^{93}$ supported this association, whereas other published studies by Higuchi ${ }^{63}$ and Tamura ${ }^{14}$ excluded it.

Some authors ${ }^{94-96}$ suggested an association between decreased intracranial pressure due to CSF, which is a common finding in $\mathrm{AD}$, and NTG; however, Tsukahara ${ }^{97}$ found normal intracranial pressure in a cohort of patients with NTG, and rejected this hypothesis. The Tau protein has also been suggested as a possible common etiopathogenic factor, since it is present both in the CSF of AD patients ${ }^{98}$ and in the horizontal cells in the retina of glaucoma patients. ${ }^{99}$ However, the most promising studies indicate the amyloid- $\beta$ protein as the common pathogenetic factor for both disease ${ }^{10,11,77,90,100}$ In fact, this aberrant protein was found in the vitreous humor of patients with glaucoma and seems to be involved in RGC death. Finally, other authors suggested a role played by Helicobacter pylori infection, ${ }^{101,102}$ or by mutations in the gene that encodes for optineurin. ${ }^{16}$ The first hypothesis does not seem to have many followers, whereas research on optineurin recently provided a clue that this protein may be indeed a new common underlying risk factor involved in both NTG and AD. ${ }^{103}$ Optineurin is a hydrophilic, cytosolic protein ${ }^{10}$ that is ubiquitously expressed in brain and in ocular tissues including the retina, trabecular meshwork and non-pigmented ciliary epithelium. In the retina, RGCs are immunolabeled with high intensity. ${ }^{104,105}$ Interestingly, optineurin was found in neurofibrillary tangles and dystrophic neurites in AD, thus suggesting a new hypothesis for neurodegeneration in $\mathrm{AD}$ involving chronic optineurin neurotoxicity and mimicking NTG at the molecular level. ${ }^{106}$

Another common risk factor seems to be hyper-homocysteinemia (HHcy). ${ }^{107-109}$ Homocysteine is a non-protein amino acid and a metabolic precursor of both methionine and cysteine. ${ }^{110}$ Recent epidemiological studies have found that mild to moderate HHcy, is also a risk factor for sporadic AD. ${ }^{111-113}$ Zhuo and Praticò in $2010^{114}$ measured homocysteine levels and amyloidogenesis in Tg2576 mice (a well-established mouse model of AD-like amyloidosis ${ }^{115}$ ) fed with a diet containing excessive methionine and deficient in vitamins of the B group, in order to increase homocysteine levels in vivo. ${ }^{116-117}$ After 7 months on this diet, they found a severe HHcy in Tg2576 mice, but the diet failed to cause any significant alterations in $A \beta$ levels, deposition, or A $\beta P P$ metabolism. However, a recent clinical study on a cohort of patients with POAG or pseudoexfoliation glaucoma ${ }^{118}$ failed to find a correlation between POAG and plasma homocysteine levels. Therefore, further studies are needed to clarify the role of HHcy in neuronal pathologies. ${ }^{116,119}$

\section{Therapeutic strategies for alzheimer's disease}

Acetylcholinesterase inhibitors: The key existing treatments for $\mathrm{AD}$ are symptomatic rather than disease modifying in nature. Acetylcholinesterase inhibitors such as donepezil, rivastigmine and 
galantamine are well-established symptomatic treatments for AD. They are recommended as first-line therapy by the Quality Standards Subcommittee of the American Academy of Neurology for the symptomatic treatment of $\mathrm{AD} .{ }^{120}$ The rationale for the development of these drugs derives from the cholinergic hypothesis, suggesting that cognitive impairment in $\mathrm{AD}$ is the result of cholinergic synaptic dysfunction in the hippocampus and neocortex, caused by early cholinergic neuron degradation. ${ }^{120}$ Acetylcholinesterase inhibitors work by inhibiting degradation of acetylcholine released into synaptic clefts, thereby improving cholinergic neurotransmission. A recent Cochrane review concluded that donepezil, rivastigmine and galantamine are efficacious in mild-to-moderate AD. ${ }^{121}$

The therapeutic role of acetylcholinesterase inhibitors in $\mathrm{AD}$ poses the question of whether a therapeutic benefit may also exist in glaucoma. A significant proportion of NTG patients have been found to have an AD-like cerebral blood flow pattern. ${ }^{122}$ In this group of patients, a subsequent pilot study found that oral donepezil significantly improved $\mathrm{ON}$ head and cerebral blood flow as well as visual field defects. ${ }^{123}$ Furthermore, some animal studies demonstrated that donepezil is able to reduce IOP when applied topically, and to significantly reduce IOP in normotensive AD patients after 4 weeks of oral intake. ${ }^{124}$ Recently, it was also demonstrated that galantamine protects RGC structure and function in a rat model of glaucoma. ${ }^{125}$ Protection was mediated through the activation of muscarinic acetylcholine receptors, and was independent of IOP. All these studies suggest that acetylcholinesterase inhibitors may have a neuroprotective role in glaucoma. However, further investigation is needed as the evidence to date remains sparse.

Glutamate modulation: Glutamate is a principal excitatory neurotransmitter in the brain. It normally binds to its NMDA receptor on postsynaptic cells to mediate normal excitatory neuronal activity: this induces long-term potentiation, which is related to memory and learning. In $\mathrm{AD}$, excessive glutamate levels and sustained low activation of NMDA receptors lead to neuronal excitotoxicity, which is hypothesized to play a key role in $\mathrm{AD} .{ }^{126}$ This is due to an excessive calcium influx through the receptor-associated ion channel and subsequent free radical formation, which in turn leads to neurodegeneration. ${ }^{127} \mathrm{~A}$ number of factors, such as $\mathrm{A} \beta$ oligomers $^{128,129}$ and ApoE- $\varepsilon 4^{130}$ have been demonstrated to play a role in this mechanism. Various agents have been developed to modulate glutamatergic neuro-excitotoxicity. Among these, the US FDA licensed the use of memantine for the symptomatic treatment of AD. ${ }^{131}$ It is a noncompetitive, low-affinity NMDA receptor antagonist that preferentially blocks excessive NMDA receptor activation, without disrupting the physiological NMDA receptor activity required for cognitive function. ${ }^{132}$ There is also preclinical evidence in AD suggesting that memantine may have a neuroprotective role in $\mathrm{AD}$, as well as being a symptomatic treatment. ${ }^{133}$ It has been shown by randomized controlled trials that memantine can improve cognition, behavior and activities of daily living in people with moderate-tosevere $\mathrm{AD},{ }^{134}$ even if there is no evidence of a therapeutic benefit in mild $\mathrm{AD} .{ }^{135}$ It should be noted that combined therapy with memantine and donepezil in patients with moderate-to-severe $\mathrm{AD}$ resulted in better cognition, behavior, activities of daily living and global outcome as compared with donepezil alone. ${ }^{136}$ Glutamatemediated neurotoxicity is thought to also play a role in glaucoma. In fact, the association between RGC death and glutamate toxicity has been shown in several glaucoma animal models. ${ }^{137}$ Memantine has been demonstrated to be protective against NMDA-induced neuronal loss in vitro. ${ }^{138}$ Application of memantine in vivo significantly increased RGC survival in a DBA/2J transgenic mouse model of glaucoma ${ }^{139}$ in an ischemic rabbit model, ${ }^{140}$ and in ischemic and hypertensive rat models. ${ }^{141}$ Memantine has further been shown to protect against structural and functional RGC loss in a monkey model of glaucoma. ${ }^{27}$ In addition, monkeys affected by glaucoma and treated with memantine demonstrated significantly less neuronal shrinkage in the lateral geniculate nucleus, which is the principal target of RGCs. ${ }^{142}$ It is noteworthy that memantine is the only neuroprotective drug that has completed a Phase III clinical trial in OAG. Unfortunately, the drug was found to be ineffective with regard to its primary end point of improving the visual field. ${ }^{26}$ Another noncompetitive antagonist of the NMDA receptor, MK-801, has similar functions to memantine but is not used in $\mathrm{AD}$ as it can cause schizophrenic symptoms. MK-801 has been found to protect RGCs in vitro as well as in vivo in various animal models of glaucoma. ${ }^{143}$

Alternative approaches: The obvious limits of the above treatments led scientists to develop alternative therapeutic approaches. Preclinical experiments in transgenic mice suggested that passive immunization with antibodies against the beta amyloid protein might counteract the progression of AD in humans. ${ }^{144-146}$ Currently, several conformation- and oligomeric-specific antibodies targeting the Alzheimer's amyloid beta oligomers (AbOs) have been developed. However, they appear largely not exploitable for subcellular targeting and intracellular functional studies in living cells. In 2014 Meli et al. generated, by an in vivo intracellular selection in yeast cells, a set of conformation-sensitive antibody fragments for different subcellular compartments, ${ }^{147}$ developing a CSI method. This approach allowed determining the cellular mechanisms of $\mathrm{AbO}$ generation, demonstrating that intracellular amyloid bodies can oligomerize into pathological forms through critical conformations formed inside the endoplasmic reticulum (ER). The anti-AbO intrabody selectively intercepts critical $\mathrm{AbO}$ conformers and controls their 'toxic' assembly in the ER, without interfering with the complex processes of maturation and processing of APP. ${ }^{147}$

As regards the relationship between $\mathrm{AD}$ and POAG, Cheung and co-workers were among the first to suggest that, since the neurodegeneration that affects patients with glaucoma refers to similar pathogenic mechanisms as $\mathrm{AD}$ and $\mathrm{PD}$ (glutamate excitotoxicity, mitochondrial dysfunction, protein misfolding, oxidative stress, inflammation and deprivation of neurotrophins), then, also from a therapeutic point of view, such neurodegeneration can be dealt with by similar therapeutic strategies. ${ }^{148}$ In support of this concept, many publications support the use of molecules traditionally employed in the treatment of classic neurodegenerative diseases also in the treatment of glaucoma. ${ }^{149}$ Bakalash et al. ${ }^{150}$ evaluated the effect of glatiramer acetate in mouse models of glaucoma demonstrating the increased expression of EGR-1, a nuclear transcription factor involved in the phenomenon of neuronal plasticity with neuroprotective effect. Estermann et al. in $2006^{124}$ documented a hypotonic effect by donepezil (Aricept), a selective inhibitor of acetylcholinesterase used in the treatment of AD, on 32 normotensive patients. Tatton et al. ${ }^{149}$ on the other hand, believe that $\alpha 2$-adrenergic receptor agonists (e.g., brimonidine) have a neuroprotective role both in $\mathrm{AD}$ and in glaucoma. Lee and co-workers, in 2012, observed a reduction of $\beta$-amyloid in laboratory mice who were given vitamin D3. ${ }^{151}$ In recent years there has been a growing interest in epigallocatechin gallate (EGCG), a component of green tea, in the context for neuroprotection in glaucoma and Alzheimer's. In 2008 Osborne $^{39}$ demonstrated that 
in a rat model of retinal ischemia due to a sudden elevation of IOP, ECGC is able to prevent apoptosis in ganglion cells by protecting mitochondrial function. These results were further confirmed by Zhang et al. ${ }^{152}$ who recorded the electroretinograms (ERGs) of eyes from ischemia-induced rats. ECGC properties were also evaluated in humans by Falsini et al. ${ }^{153}$ and the obtained PERG results suggested that EGCG might favorably influence inner retinal function in eyes with early to moderately advanced glaucomatous damage. It seems that ECGC might also have protective effects on AD: in $2012 \mathrm{He}$ et al. ${ }^{154}$ evaluated the beneficial effects of ECGC by immunohistochemical analysis of APP in the hippocampus of an AD mouse model. Further, Zhang et al. ${ }^{155}$ reported that the polyphenol (-)-EGCG is able to inhibit A $\beta$ oligomerization.

Homotaurine also deserves a specific mention. Homotaurine is a molecule that has been extensively investigated as a neuroprotector in $\mathrm{AD}$. It is a small aminosulfonate compound that is present in different species of red marine algae and it has been shown, in both in vitro and in vivo models, to be able to provide a relevant neuroprotective effect by its specific anti-amyloid activity and by its $\gamma$-aminobutyric acid type A receptor affinity. Homotaurine may prevent the formation of the insoluble beta-amyloid complex, thus preventing its related neurotoxicity. ${ }^{156}$ The ALPHASE study, recently published by Aisen et al. in 2011, enrolled 1052 patients affected by AD, and showed that homotaurine treatment may prevent further cognitive decline and loss of memory in these patients, as well as a reduction in global cognitive decline in APOE4 allele carriers, suggesting disease-modifying effects. ${ }^{157}$ This functional result is correlated to the anatomical finding of a lesser decrease in the hippocampal volume in those patients treated with the oral supplement of homotaurine. Since amyloid plaques have also been shown to occur in RGC as a consequence of elevated IOP levels ${ }^{158-159}$ beta amyloid appears to be a possible target in glaucoma neuroprotection. ${ }^{160}$

Another promising molecule is forskolin, a diterpene extracted from the roots of Coleus Forskohlii, a plant growing in India. It lowers IOP through a receptor-independent increase of cyclic adenosine monophosphate (cAMP) that finally results in a decrease of the inflow of AH in the eye chambers. ${ }^{161}$ Moreover, the increased levels of cAMP also result in PKA activation and Rho kinase inhibition, in turn causing the disassembly of the actin cytoskeleton in the trabecular meshwork. This process enhances the permeability of the trabecular meshwork to the AH outflow, also contributing to a decrease of IOP. ${ }^{162}$ Accordingly, topically applied forskolin has been shown to lower IOP in both rabbit and monkey model systems. ${ }^{163}$ Such an effect has also been replicated in humans by oral systemic treatment, and two different publications ${ }^{21}$ indicated that forskolin given to POAG patients under maximum tolerated medical therapy is able to exert a further hypotonizing effect, significantly decreasing IOP irrespective of the drug regimen present. Besides its effects on IOP, cAMP is also able to enhance neuronal and RGC survival, and induce specific beta-amyloid phagocytic activities in microglia cells. The anti-apoptotic effects of cAMP are seen in many types of neuronal systems, including cerebellar granule neurons, ${ }^{164-169}$ dopamine neurons, ${ }^{170}$ septal cholinergic neurons, ${ }^{171}$ and sympathetic and sensory neurons. ${ }^{172-174}$ A clinical study on POAG patients treated with a food supplement containing forskolin and rutin (Kronek $\left.{ }^{\circledR}\right)$ has shown an improvement of the electrophysiological activity of RGC as measured by PERG analysis. ${ }^{175,176}$

Carnosine is a di-peptide (alanine + histidine), found in large amounts in the eye lens, the brain (especially the primary olfactory ways) $(5 \mathrm{mM})$ and in voluntary muscles $(20 \mathrm{mM}) .{ }^{177}$ It has been shown to have neuroprotective effects on RGCs against glutamate and free radical toxicity, ${ }^{178,179}$ and also attenuate through similar mechanisms $\beta$-amyloid neurotoxicity. ${ }^{179}$ In the context of $\mathrm{AD}$, carnosine has been suggested as a therapeutic agent, given its capability to act as a metal chelator, free radical scavenger as well as an inhibitor of $A \beta$ toxicity. ${ }^{178}$ In 2011 Corona et al. investigated the potential beneficial effects of dietary carnosine supplementation $(10 \mathrm{mM}$ in drinking water) in $3 \times \mathrm{Tg}-\mathrm{AD}$ mice, ${ }^{180}$ an $\mathrm{AD}$ animal model that develops an amyloidand tau-dependent pathology, as well as AD-related cognitive deficits. ${ }^{171-181}$ When Corona et al. analyzed the effects of carnosine on this mouse model system, they found that carnosine was very effective in decreasing intraneuronal $A \beta$ deposition in the hippocampus. Analysis of the effect of carnosine supplementation on cognitive deficits of 3xTg-AD mice showed a positive trend, indicating that it might also have a beneficial role in preventing long-term memory deficits. ${ }^{180}$ It is interesting to note that the association of these three molecules (homotaurine, forskolin and carnosine), which is present

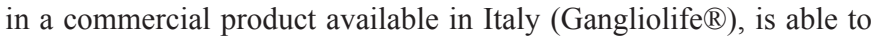
protect RGCs in vitro by two different neurotoxic molecules such as rotenone and sodium azide. ${ }^{181,182}$ Finally, a new drug potentially useful in the treatment of both diseases is ademetionine, an antidepressant (depression is one of the main psychiatric symptoms of AD) that appears to reduce the aggregation of $\beta$-amyloid fibrils ${ }^{183,184}$ and shows neuroprotective effects on RGCs. ${ }^{185,186}$

\section{Conclusion}

According to what has been illustrated here, the emerging message is an encouragement to healthcare professionals involved in the management of $\mathrm{AD}$ (Geriatricians, Neurologists, etc.) to also include, as part of multi-disciplinary assessment of the elderly patient, a systematic ophthalmic examination, aimed at evaluating the risk factors for glaucoma disease and the status of visual function in general. We also need to give serious consideration to the possibility of using certain medications in both of these diseases. Numerous publications, in fact, confirm that what protects the nervous system from neurodegeneration (e.g. forskolin, L-carnosine, homotaurine, folic acid, acetylcholinesterase inhibitors, antioxidant vitamins, glatiramer acetate, etc.), also protects RGCs, delaying the visual decline and improving patients' quality of life.

\section{Acknowledgments}

The authors acknowledge the critical proof reading of the manuscript by Dr Antony Bridgewood.

\section{Conflicts of interest}

N. Pescosolido, A. Pascarella and G. Buomprisco report no conflicts of interest and have no proprietary interest in any of the materials mentioned in this article. D. Rusciano is a full time employee of Sooft SpA, the Italian pharmaceutical company that produces and commercializes the food supplement Gangliolife.

\section{References}

1. Bizrah M, Guo L, Cordeiro MF. Glaucoma and Alzheimer's disease in the elderly. Aging Health. 2011;7(5):719-733.

2. Sommer A, Tielsch JM, Katz J, et al. Relationship between intraocular pressure and primary open angle glaucoma among white and black Americans. The Baltimore Eye Survey. Arch Ophthalmol. 1991;109(8):1090-1095. 
3. Cedrone C, Mancino R, Cerulli A, et al. Epidemiology of primary glaucoma: prevalence, incidence, and blinding effects. Prog Brain Res. 2008;173:3-14.

4. Dawson TM, Dawson VL. Molecular pathways of neurodegeneration in Parkinson's disease. Science. 2003;302(5646):819-822.

5. Jankovic J. Parkinson's disease: clinical features and diagnosis. J Neurol Neurosurg Psychiatr. 2008;79(4):368-376.

6. Wenk GL. Neuropathologic changes in Alzheimer's disease. J Clin Psychiatry. 2003;64(Suppl 9):7-10.

7. Tiraboschi P, Hansen LA, Thal LJ, et al. The importance of neuritic plaques and tangles to the development and evolution of AD. Neurology. 2004;62(11):1984-1989.

8. Shoghi-Jadid K, Small GW, Agdeppa ED, et al. Localization of neurofibrillary tangles and beta-amyloid plaques in the brains of living patients with Alzheimer disease. Am $J$ Geriatr Psychiatry. 2002;10(1):24-35.

9. Harris JA, Devidze N, Verret L, et al. Transsynaptic progression of amyloid- $\beta$-induced neuronal dysfunction within the entorhinalhippocampal network. Neuron. 2010;68(3):428-441.

10. Yin $\mathrm{H}$, Chen $\mathrm{L}$, Chen $\mathrm{X}$, et al. Soluble amyloid beta oligomers may contribute to apoptosis of retinal ganglion cells in glaucoma. Med Hypotheses. 2008;71(1):77-80.

11. Janciauskiene S, Krakau T. Alzheimer's peptide: a possible link between glaucoma, exfoliation syndrome and Alzheimer's disease. Acta Ophthalmol Scand. 2001;79(3):328-329.

12. Bayer AU, Ferrari F. Severe progression of glaucomatous optic neuropathy in patients with Alzheimer's disease. Eye (Lond). 2002;16(2):209-212.

13. McKinnon SJ. Glaucoma: ocular Alzheimer's disease? Front Biosci. 2003;8:s1140-s1156.

14. Tamura H, Kawakami H, Kanamoto T, et al. High frequency of openangle glaucoma in Japanese patients with Alzheimer's disease. J Neurol Sci. 2006;246(1-2):79-83.

15. Phillips ECI. Alzheimer's disease and glaucoma. $\mathrm{Br} J$ Ophthalmol. 2011;95(1):152-153.

16. Tian T, Liu YH. Normal-tension glaucoma and Alzheimer's disease: retinal vessel signs as a possible common underlying risk factor. Med Hypotheses. 2011;77(3):466-467.

17. Bach-Holm D, Kessing SV, Mogensen U, et al. Normal tension glaucoma and Alzheimer disease: comorbidity? Acta Ophthalmol. 2012;90(7):683-685.

18. Ou Y, Grossman DS, Lee PP, et al. Glaucoma, Alzheimer disease and other dementia: a longitudinal analysis. Ophthalmic Epidemiol. 2012;19(5):285-292.

19. Venkataraman ST, Flanagan JG, Hudson C. Vascular reactivity of optic nerve head and retinal blood vessels in glaucoma--a review. Microcirculation. 2011;17(7):568-581.

20. Nilforushan N. Neuroprotection in glaucoma. $J$ Ophthalmic Vis Res. 2012;7(1):91-93.

21. Pescosolido N, Librando A. Oral administration of an association of forskolin, rutin and vitamins B1 and B2 potentiates the hypotonising effects of pharmacological treatments in POAG patients. Clin Ter. 2010;161(3):e81-e85.

22. McKinnon SJ. The cell and molecular biology of glaucoma: common neurodegenerative pathways and relevance to glaucoma. Invest Ophthalmol Vis Sci. 2012;53(3):2485-2487.
23. Kim TW, Kim DM, Park KH, et al. Neuroprotective effect of memantine in a rabbit model of optic nerve ischemia. Korean $J$ Ophthalmol. 2002;16(1):1-7.

24. Osborne NN. Recent clinical findings with memantine should not mean that the idea of neuroprotection in glaucoma is abandoned. Acta Ophthalmol. 2009;87(4):450-454.

25. Chidlow G, Wood JP, Casson RJ. Pharmacological neuroprotection for glaucoma. Drugs. 2007;67(5):725-759.

26. Sena DF, Ramchand K, Lindsley K. Neuroprotection for treatment of glaucoma in adults. Cochrane Database Syst Rev. 2010;2:CD006539.

27. Nagahara AH, Merrill DA, Coppola G, et al. Neuroprotective effects of brain-derived neurotrophic factor in rodent and primate models of Alzheimer's disease. Nat Med. 2009;15(3):331-337.

28. Harper MM, Grozdanic SD, Blits B, et al. Transplantation of BDNFsecreting mesenchymal stem cells provides neuroprotection in chronically hypertensive rat eyes. Invest Ophthalmol Vis Sci. 2011;52(7):4506-4515.

29. Chader GJ. Advances in glaucoma treatment and management: neurotrophic agents. Invest Ophthalmol Vis Sci. 2012;53(5):2501-2505.

30. Szekely CA, Zandi PP. Non-steroidal anti-inflammatory drugs and Alzheimer's disease: the epidemiological evidence. CNS Neurol Disord Drug Targets. 2010;9(2):132-139.

31. Izzotti A, Bagnis A, Sacca SC. The role of oxidative stress in glaucoma Mutat Res. 2006;612(2):105-114.

32. Dilsiz N, Sahaboglu A, Yildiz MZ, et al. Protective effects of various antioxidants during ischemia-reperfusion in the rat retina. Graefes Arch Clin Exp Ophthalmol. 2006;244(5):627-633.

33. Behl C, Moosmann B. Antioxidant neuroprotection in Alzheimer's disease as preventive and therapeutic approach. Free Radic Biol Med. 2002;33(2):182-191.

34. Bachurin SO, Shevtsova EP, Kireeva EG, et al. Mitochondria as target for neurotoxins and neuroprotective agents. Ann N Y Acad Sci. 2003;993:334-344.

35. Osborne NN, Lascaratos G, Bron AJ, et al. A hypothesis to suggest that light is a risk factor in glaucoma and the mitochondrial optic neuropthies. Br J Ophthalmol. 2006;90(2):237-241.

36. Osborne NN, Alvarez CN, Del Olmo Aguado S. Targeting mitochondrial dysfunction as in aging and glaucoma. Drug Discov Today. 2014;19(10):1613-1622.

37. Osborne NN, Del Olmo Aguado S. Maintenance of retinal ganglion cell mitochondrial functions as a neuroprotective strategy in glaucoma. Curr Opin Pharmacol. 2013;13(1):16-22.

38. Osborne NN. Mitochondria: their role in ganglion cell death ad survival I primary open angle glaucoma. Exp Eye Res. 2010;90(6):750-757.

39. Osborne NN. Pathogenesis of ganglion "cell death" in glaucoma and neuroprotection: focus on ganglion cell axonal mitochondria. Prog Brain Res. 2008;173:339-352.

40. Brookmeyer R, Johnson E, Ziegler-Graham K, et al. Forecasting the global burden of Alzheimer's disease. Alzheimers Dement. 2007;3(3):186-191.

41. Bates KA, Sohrabi HR, Rodrigues M, et al. Association of cardiovascular factors and Alzheimer's disease plasma amyloid-beta protein in subjective memory complainers. J Alzheimers Dis. 2009;17(2):305-318.

42. Folstein MF, Folstein SE, McHugh PR. "Mini-mental state". A practical method for grading the cognitive state of patients for the clinician. $J$ Psychiatr Res. 1975;12(3):189-198. 
43. Jack CR Jr. Alzheimer disease: new concepts on its neurobiology and the clinical role imaging will play. Radiology. 2012;263(2):344-361.

44. Huang Y, Mucke L. Alzheimer mechanisms and therapeutic strategies. Cell. 2012;148(6):1204-1222.

45. Yamada M, Naiki H. Cerebral amyloid angiopathy. Prog Mol Biol Trans Sci. 2012;107:41-78.

46. Revesz T, Holton JL, Lashley T, et al. Sporadic and familial cerebral amyloid angiopathies. Brain Pathol. 2002;12(3):343-357.

47. Cabral D, Beach TG, Vedders L, et al. Frequency of Alzheimer's disease pathology at autopsy in patients with clinical normal pressure hydrocephalus. Alzheimers Dement. 2011;7(5):509-513.

48. Sadun AA, Borchert M, DeVita E, et al. Assessment of visual impairment in patients with Alzheimer's disease. Am J Ophthalmol. 1987;104(2):113-120.

49. Katz B, Rimmer S. Ophthalmologic manifestations of Alzheimer's disease. Surv Ophthalmol. 1989;34(1):31-43.

50. Mendola JD, Cronin-Golomb A, Corkin S, et al. Prevalence of visual deficits in Alzheimer's disease. Optom Vis Sci. 1995;72(3): 155-167.

51. Trick GL, Trick LR, Morris P, et al. Visual field loss in senile dementia of the Alzheimer's type. Neurology. 1995;45(1):68-74.

52. Whittaker KW, Burdon MA, Shah P. Visual field loss and Alzheimer's disease. Eye. 2002;16:206-208.

53. Lakshminarayanan V, Lagrave J, Kean ML, et al. Vision in dementia: contrast effects. Neurol Res. 1996;18(1):9-15.

54. Crown RW, Levin LB, LaBree L, et al. Sweep visual evoked potential evaluation of contrast sensitivity in Alzheimer's dementia. Invest Ophtalmol Vis Sci. 2003;44(2):875-878.

55. Morrison JH, Hof PR, Bouras C. An anatomic substrate for visual disconnection in Alzheimer's disease. Ann N Y Acad Sci. 1991;640:36-43.

56. Gilmore GC, Wenk HE, Naylor LA, Koss E. Motion perception and Alzheimer's disease. J Gerontol. 1994;49(2):52-57.

57. McKee AC, Au R, Cabral HJ, Kowall NW, et al. Visual association pathology in preclinical Alzheimer disease. J Neuropathol Exp Neurol. 2006;65(6):621-630.

58. Ho WL, Leung Y, Tsang AW, et al. Review: tauopathy in the retina and optic nerve: does it shadow pathological changes in the brain? Mol Vis. 2012;18:2700-2710.

59. Kono K, Miyao M, Ishihara S, et al. Hypersensitivity in the pupil dilation response to a cholinergic antagonist in patients with Alzheimer's disease and Down's syndrome. Nihon Ronen Igakkai Zasshi. 1996;33(11):829-834.

60. Arai $H$, Terajima M, Nakagawa $T$, et al. Pupil dilatation assay by tropicamide is modulated by apolipoprotein E epsilon 4 allele dosage in Alzheimer's disease. Neuroreport. 1996;7(4):918-920.

61. Fridh M, Havelius U, Elofsson G, et al. The pupillary response to tropicamide in Alzheimer's disease. Acta Ophthalmol Scand. 1996;74(3):276-279.

62. Loupe DN, Newman NJ, Green RC, et al. Pupillary response to tropicamide in patients with Alzheimer disease. Ophthalmology. 1996;103(3):495-503.

63. Higuchi S, Matsushita S, Hasegawa Y, et al. Apolipoprotein E epsilon 4 allele and pupillary response to tropicamide. Am J Psychiatry. 1997;154(5):694-696.
64. Granholm E, Morris S, Galasko D, et al. Tropicamide effects on pupil size and pupillary light reflexes in Alzheimer's and Parkinson's disease. Int J Psychophysiol. 2003;47(2):95-115.

65. Hou RH, Samuels ER, Raisi M, et al. Why patients with Alzheimer's disease may show increased sensitivity to tropicamide eye drops: role of locus coeruleus. Psychopharmacology. 2006;184(1):95-106.

66. Fotiou F, Fountoulakis KN, Tsolaki M, et al. Changes in pupil reaction to light in Alzheimer's disease patients: a preliminary report. Int $J$ Psychophysiol. 2000;37(1):111-120.

67. Fotiou DF, Brozou CG, Haidich AB, et al. Pupil reaction to light in Alzheimer's disease: evaluation of pupil size changes and mobility. Aging Clin Exp Res. 2007;19(5):364-371.

68. Treloar AJ, Assin M, Macdonald AJ. Pupillary response to topical tropicamide as a marker for Alzheimer's disease. Br J Clin Pharmacol. 1996;41(3):256-257.

69. KurzA, Marquard R, Fremke S, et al. Pupil dilation response to tropicamide: a biological test for Alzheimer's disease? Pharmacopsychiatry. 1997;30(1):12-15.

70. Reitner A, Baumgartner I, Thuile $\mathrm{C}$, et al. The mydriatic effect of tropicamide and its diagnostic use in Alzheimer's disease. Vision Res. 1997;37(1):165-168.

71. Prettyman R, Bitsios P, Szabadi E. Altered pupillary size and darkness and light reflexes in Alzheimer's disease. J Neurol Neurosurg Psychiatry. 1997;62(6):665-668.

72. Growdon JH, Graefe K, Tennis M, et al. Pupil dilation to tropicamide is not specific for Alzheimer disease. Arch Neurol. 1997;54(7):841-844.

73. Frederikse PH, Garland D, Zigler JS Jr, et al. Oxidative stress increases production of beta-amyloid precursor protein and beta-amyloid (Abeta) in mammalian lenses, and Abeta has toxic effects on lens epithelial cells. $J$ Biol Chem. 1996;271(17):10169-10174.

74. Goldstein LE, Muffat JA, Cherny RA, et al. Cytosolic beta-amyloid deposition and supranuclear cataracts in lenses from people with Alzheimer's disease. Lancet. 2003;361(9365):1258-1265.

75. Paquet $\mathrm{C}$, Boissonnot $\mathrm{M}$, Roger $\mathrm{F}$, et al. Abnormal retinal thickness in patients with mild cognitive impairment and Alzheimer's disease. Neurosci Lett. 2007;420(2):97-99.

76. Berisha F, Feke GT, Trempe CL, et al. Retinal abnormalities in early Alzheimer's disease. Invest Ophthalmol Vis Sci. 2007;48(5):2285-2289.

77. Yoneda S, Hara H, Hirata A, et al. Vitreous fluid levels of betaamyloid and tau in patients with retinal diseases. Jpn J Ophthalmol. 2005;49(2):106-108.

78. Tsai CS, Ritch R, Schwartz B, et al. Optic nerve head and nerve fiber layer in Alzheimer's disease. Arch Ophthalmol. 1991;109(2):199-204.

79. Hedges TR 3rd, Perez Galves R, Speigelman D, et al. Retinal nerve fiber layer abnormalities in Alzheimer's disease. Acta Ophthalmol Scand. 1996;74(3):271-275.

80. Danesh Meyer HV, Birch H, Ku JY, et al. Reduction of optic nerve fibers in patients with Alzheimer disease identified by laser imaging. Neurology. 2006;67(10):1852-1854.

81. Chandra V, Bharucha NE, Schoenberg BS. Conditions associated with Alzheimer's disease at death: Case-control study. Neurology. 1986;36(2):209-211. 
82. Bayer AU, Ferrari F, Erb C. High occurrence rate of glaucoma among patients with Alzheimer's disease. Eur Neuro. 2002;47(3):165-168.

83. Bayer AU, Keller ON, Ferrari F, et al. Association of glaucoma with neurodegenerative diseases with apoptotic cell death: Alzheimer's disease and Parkinson's disease. Am J Ophthalmol. 2002;133(1):135-137.

84. Yochim BP, Mueller AE, Kane KD, et al. Prevalence of cognitive impairment, depression, and anxiety symptoms among older adults with glaucoma. J Glaucoma. 2012;21(4):250-254.

85. Nesher R, Trick GL. The pattern electroretinogram in retinal and optic nerve disease. A quantitative comparison of the pattern of visual dysfunction. Doc Ophthalmol. 1991;77(3):225-235.

86. Kessing LV, Lopez AG, Andersen K, et al. No increased risk of developing Alzheimer disease in patients with glaucoma. J Glaucoma. 2007;16(1):47-51.

87. Hinton DR, Sadun AA, Blanks JC, et al. Optic-nerve degeneration in Alzheimer's disease. $N$ Engl J Med. 1986;315(8):485-487.

88. Sadun AA, Bassi CJ. Optic nerve damage in Alzheimer's disease. Ophthalmology. 1990;97(1):9-17.

89. Janciauskiene S, Westin K, Grip O, et al. Detection of Alzheimer peptides and chemokines in the aqueous humor. Eur $J$ Ophthalmol. 2011;21(1):104-111.

90. Guo L, Salt TE, Luong V, et al. Targeting amyloid-beta in glaucoma treatment. Proc Natl Acad Sci. 2007;104(33):13444-13449.

91. Copin B, Brezin AP, Valtot F, et al. Apolipoprotein E-promoter singlenucleotide polymorphisms affect the phenotype of primary open-angle glaucoma and demonstrate interaction with the myocilin gene. Am J Hum Genet. 2002;70(6):1575-1581.

92. Vickers JC, Craig JE, Stankovich J, et al. The apolipoprotein epsilon4 gene is associated with elevated risk of normal tension glaucoma. Mol Vis. 2002;8:389-393.

93. Kountouras J, Gavalas E, Boziki M, et al. Apolipoprotein E polymorphisms in patients with primary open-angle glaucoma. $\mathrm{Am} J$ Ophthalmol. 2007;144(4):638-639.

94. Silverberg G, Mayo M, Saul T, et al. Elevated cerebrospinal fluid pressure in patients with Alzheimer's disease. Cerebrospinal Fluid Res. 2006;3:7.

95. Wostyn P, Audenaert K, De Deyn PP. Alzheimer's disease-related changes in diseases characterized by elevation of intracranial or intraocular pressure. Clin Neurol Neurosurg. 2008;110(2):101-109.

96. Wostyn P, Audenaert K, De Deyn PP. Alzheimer's disease and glaucoma: is there a causal relationship? Br J Ophthalmol. 2009;93(12):1557-1559.

97. Tsukahara S, Hasaka O, Hoshi H, et al. Pathological cupping in normal pressure glaucoma is probably not due to low CSF pressure. Acta Ophthalmol Scand. 1996;74(6):646.

98. Jensen M, Basun H, Lannfelt L. Increased cerebrospinal fluid tau in patients with Alzheimer's disease. Neurosci Lett. 1995;186(2-3):189-191.

99. Gupta N, Fong J, Ang LC, et al. Retinal tau pathology in human glaucomas. Can J Ophthalmol. 2008;43(1):53-60.

100. Nucci C, Martucci A, Martorana A, et al. Glaucoma progression associated with altered cerebral spinal fluid levels of amyloid beta and tau proteins. Clin Experiment Ophthalmol. 2011;39(3):279-281.

101. Kountouras J, Zavos C, Chatzopoulos D. Induction of apoptosis as a proposed pathophysiological link between glaucoma and Helicobacter pylori infection. Med Hypotheses. 2004;62(3):378-381.

102. Kountouras J, Tsolaki M, Gavalas E, et al. Relationship between Helicobacter pylori infection and Alzheimer disease. Neurology. 2006;66(6):938-940.
103. Kozulin A, Lebeer J, Madella-Noja A, et al. Cognitive modifiability of children with developmental disabilities: a multicentre study using Feuerstein's Instrumental Enrichment--Basic program. Res Dev Disabil. 2010;31(2):551-559.

104. Li Y, Kang J, Horwitz MS. Interaction of an adenovirus E3 14.7-kilodalton protein with a novel tumor necrosis factor a-inducible cellular protein containing leucine zipper domains. Mol Cell Biol. 1998;18(3):1601-1610.

105. Rezaie T, Sarfarazi M. Molecular cloning, genomic structure, and protein characterization of mouse optineurin. Genomics. 2005;85(1):131-138.

106. Liu YH, Tian T. Hypothesis of optineurin as a new common risk factor in normal-tension glaucoma and Alzheimer's disease. Med Hypotheses. 2011;77(4):591-592.

107. Chen CS, Yeh YC, Chang YS, et al. Plasma homocysteine level and apathy in Alzheimer's disease. J Am Geriatr Soc. 2011;59(9):1752-1754.

108. Ghanem AA, Mady SM, El Awady HE, et al. Homocysteine and hydroxyproline levels in patients with primary open-angle glaucoma. Curr Eye Res. 2012;37(8):712-718

109. Seshadri S. Homocysteine and the risk of dementia. Clin Chem 2012;58(6):1059-1060.

110. Jhee KH, Kruger WD. The role of cystathionine beta-synthase in homocysteine metabolism. Antioxid Redox Signal. 2005;7(5-6):813-822.

111. Seshadri S, Beiser A, Selhub J, et al. Plasma homocysteine as a risk factor for dementia and Alzheimer's disease. NEngl JMed 2002;346(7):476-483.

112. Clarke R, Smith AD, Jobst KA, et al. Folate, vitamin B12, and serum total homocysteine levels in confirmed Alzheimer disease. Arch Neurol. 1998;55(11):1449-1455.

113. Seshadri S. Elevated plasma homocysteine levels: risk factor or risk marker for the development of dementia and Alzheimer's disease? $J$ Alzheimers Dis. 2006;9(4):393-398.

114. Zhuo JM, Pratico D. Severe in vivohyper-homocysteinemia is not associated with elevation of amyloid- $\beta$ peptides in the Tg2576 Mice. $J$ Alzheimers Dis. 2010;21(1):133-140.

115. Hsiao K, Chapman P, Nilsen S, et al. Correlative memory deficits, Abeta elevation, and amyloid plaques in transgenic mice. Science. 1996;274(5284):99-102.

116. Hofmann MA, Lalla E, Lu Y, et al. Hyperhomocysteinemia enhances vascular inflammation and accelerates atherosclerosis in a murine model. J Clin Invest. 2001;107(6):675-683.

117. Watanabe M, Osada J, Aratani Y, et al. Mice deficient in cystathionine beta-synthase: animal models for mild and severe homocysteinemia. Proc Natl Acad Sci USA. 1995;92(5):1585-1589.

118. Zacharaki F, Hadjigeorgiou GM, Koliakos GG, et al. Plasma homocysteine and genetic variants of homocysteine metabolism enzymes in patients from central Greece with primary open-angle glaucoma and pseudoexfoliation glaucoma. Clin Ophthalmol. 2014;8:1819-1825.

119. Doody RS, Stevens JC, Beck C, et al. Practice parameter: management of dementia (an evidence-based review). Report of the quality standards subcommittee of the American academy of neurology. Neurology. 2001;56(9):1154-1166.

120. Contestabile A. The history of the cholinergic hypothesis. Behav Brain Res. 2011;221(2):334-340.

121. Birks J. Cholinesterase inhibitors for Alzheimer's disease. Cochrane Database Syst Rev. 2006;1:CD005593.

122. Sugiyama T, Utsunomiya K, Ota $\mathrm{H}$, et al. Comparative study of cerebral blood flow in patients with normal-tension glaucoma and control subjects. Am J Ophthalmol. 2006;141(2):394-396. 
123. Yoshida Y, Sugiyama T, Utsunomiya K, et al. A pilot study for the effects of donepezil therapy on cerebral and optic nerve head blood flow, visual field defect in normal-tension glaucoma. J Ocul Pharmacol Ther. 2010;26(2):187-192.

124. Estermann S, Daepp GC, Cattapan-Ludewig K, et al. Effect of oral donepezil on intraocular pressure in normotensive Alzheimer patients. $J$ Ocul Pharm Ther. 2006;22(1):62-67.

125. Almasieh M, Zhou Y, Kelly ME, et al. Structural and functional neuroprotection in glaucoma role of galantamine-mediated activation of muscarinic acetylcholine receptors. Cell Death Dis. 2010;1:e27.

126. Maragos WF, Greenamyre JT, Penney JB Jr, et al. Glutamate dysfunction in Alzheimer's disease: an hypothesis. Trends Neurosci. 1987;10(2):65-68.

127. Lipton SA. The molecular basis of memantine action in Alzheimer's disease and other neurologic disorders: low-affinity, uncompetitive antagonism. Curr Alzheimer Res. 2005;2(2):155-165.

128. Brito-Moreira J, Paula-Lima AC, Bomfim TR, et al. A $\beta$ oligomers induce glutamate release from hippocampal neurons. Curr Alzheimer Res. 2011;8(5):552-562.

129. De Felice FG, Velasco PT, Lambert MP, et al. A $\beta$ oligomers induce neuronal oxidative stress through an $N$-methyl-D-aspartate receptordependent mechanism that is blocked by the Alzheimer drug memantine. $J$ Biol Chem. 2007;282(15):11590-11601.

130. Chen Y, Durakoglugil MS, Xian X, et al. ApoE4 reduces glutamate receptor function and synaptic plasticity by selectively impairing ApoE receptor recycling. Proc Natl Acad Sci USA. 2010;107(26):12011-12016.

131. Robinson DM, Keating GM. Memantine: a review of its use in Alzheimer's disease. Drugs. 2006;66(11):1515-1534.

132. Lipton SA. Pathologically-activated therapeutics for neuroprotection: mechanism of NMDA receptor block by memantine and S-nitrosylation. Curr Drug Targets. 2007;8(5):621-632.

133. Danysz W, Parsons CG. The NMDA receptor antagonist memantine as a symptomatological and neuroprotective treatment for Alzheimer's disease: preclinical evidence. Int J Geriatr Psychiatry. 2003;18(Suppl 1):S23-S32.

134. Wilcock GK. Memantine for the treatment of dementia. Lancet Neurol. 2003;2(8):503-505.

135. Areosa SA, Sherriff F, McShane R. Memantine for dementia. Cochrane Database Syst Rev. 2005;3:CD003154.

136. Tariot PN, Farlow MR, Grossberg GT, et al. Memantine treatment in patients with moderate to severe Alzheimer disease already receiving donepezil: a randomized controlled trial. JAMA. 2004;291(3):317-324.

137. Guo L, Salt TE, Maass A, et al. Assessment of neuroprotective effects of glutamate modulation on glaucoma-related retinal ganglion cell apoptosis in vivo. Invest Ophthalmol Vis Sci. 2006;47(2):626-633.

138. Pellegrini JW, Lipton SA. Delayed administration of memantine prevents $N$-methyl-D-aspartate receptor-mediated neurotoxicity. Ann Neurol. 1993;33(4):403-407.

139. Schuettauf F, Quinto K, Naskar R, et al. Effects of anti-glaucoma medications on ganglion cell survival: the DBA/2J mouse model. Vision Res. 2002;42(20):2333-2337.

140. Kim TW, Kim DM, Park KH, et al. Neuroprotective effect of memantine in a rabbit model of optic nerve ischemia. Korean $J$ Ophthalmol. 2002;16(1):1-7.

141. Woldemussie E, Yoles E, Schwartz M, et al. Neuroprotective effect of memantine in different retinal injury models in rats. $J$ Glaucoma. 2002;11(6):474-480.

142. Yucel YH, Gupta N, Zhang Q, et al. Memantine protects neurons from shrinkage in the lateral geniculate nucleus in experimental glaucoma. Arch Ophthalmol. 2006;124(2):217-225.
143. Kato T. Memantine: a therapeutic drug for Alzheimer's disease and the comparison with MK-801. Nippon Yakurigaku Zasshi. 2004;124(3):145-151.

144. Ittner A, Bertz J, Suh LS, et al. Tau-targeting passive immunization modulates aspects of pathology in tau transgenic mice. $J$ Neurochem. 2014.

145. Lin X, Bai G, Lin L, et al. Vaccination induced changes in proinflammatory cytokine levels as an early putative biomarker for cognitive improvement in a transgenic mouse model for Alzheimer disease. Hum Vaccin Immunother. 2014;10(7).

146. Gu J, Congdon EE, Sigurdsson EM. Two novel Tau antibodies targeting the 396/404 region are primarily taken up by neurons and reduce Tau protein pathology. J Biol Chem. 2013;288(46):33081-33095.

147. Meli G, Lecci A, Manca A, et al. Conformational targeting of intracellular $\mathrm{A} \beta$ oligomers demonstrates their pathological oligomerization inside the endoplasmic reticulum. Nat Commun. 201415:3867.

148. Cheung W, Guo L, Cordeiro MF. Neuroprotection in Glaucoma: DrugBased Approaches. Optom Vis Sci. 2008;85(6):406-416.

149. Tatton W, Chen D, Chalmers-Redman R, et al. Hypothesis for a common basis for neuroprotection in glaucoma and Alzheimer's disease: antiapoptosis by alpha-2-adrenergic receptor activation. Surv Ophtalmol. 2003;48(Suppl 1):S25-S37.

150. Bakalash S, Pham M, Koronyo Y, et al. Egr1 expression is induced following glatiramer acetate immunotherapy in rodent models of glaucoma and Alzheimer's disease. Invest Ophthalmol Vis Sci. 2011;52(12):9033-9046.

151. Lee V, Rekhi E, Hoh Kam J, et al. Vitamin D rejuvenates aging eyes by reducing inflammation, clearing amyloid beta and improving visual function. Neurobiol Aging. 2012;33(10):2382-2389.

152.Zhang B, Rusciano D, Osborne NN. Orally administered epigallocatechin gallate attenuates retinal neuronal death in vivo and light-induced apoptosis in vitro. Brain Res. 2008;1198:141-152.

153. Falsini B, Marangoni D, Salgarello T, et al. Effect of epigallocatechingallate on inner retinal function in ocular hypertension and glaucoma: a short-term study by pattern electroretinogram. Graefes Arch Clin Exp Ophthalmol. 2009;247(9):1223-1233.

154. He M, Liu MY, Wang S, et al. Research on EGCG improving the degenerative changes of the brain in $\mathrm{AD}$ model mice induced with chemical drugs. Zhong Yao Cai. 2012;35(10):1641-1644.

155. Zhang T, Zhang J, Derreumaux P, et al. Molecular mechanism of the inhibition of EGCG on the Alzheimer A $\beta(1-42)$ dimer. $J$ Phys Chem B. 2013;117(15):3993-4002.

156. Caltagirone C, Ferrannini L, Marchionni N, et al. The potential protective effect of tramiprosate (homotaurine) against Alzheimer's disease: a review. Aging Clin Exp Res. 2012;24(6):580-587.

157. Aisen PS, Gauthier S, Ferris SH, et al. Tramiprosate in mild-to-moderate Alzheimer's disease-a randomized, double-blind, placebo-controlled, multi-centre study (the Alphase Study). Arch Med Sci. 2010;7(1):102-111.

158. Kipfer-Kauer A, McKinnon SJ, Frueh BE, et al. Distribution of amyloid precursor protein and amyloid-beta in ocular hypertensive C57BL/6 mouse eyes. Curr Eye Res. 2010;35(9):828-834.

159. Ito $Y$, Shimazawa $M$, Tsuruma K, et al. Induction of amyloid- $\beta$ (1-42) in the retina and optic nerve head of chronic ocular hypertensive monkeys. Mol Vis. 2012;18:2647-2657.

160. Caprioli J, Sears M. The adenylate cyclase receptor complex and aqueous humor formation. Yale J Biol Med. 1984;57(3):283-300.

161. Zhang M, Maddala R, Rao PV. Novel molecular insights into RhoA GTPase-induced resistance to aqueous humor outflow through the trabecular meshwork. Am J Physiol cell physiol. 2008;295(5):C1057C1070. 
162. Ramachandran C, Satpathy M, Mehta D, et al. Forskolin induces myosin light chain dephosphorylatio in bovine trabecular meshwork cells. Curr Eye Res. 2008;33(2):169-176.

163. Caprioli J, Sears M. Forskolin lowers intraocular pressure in rabbits, monkeys, and man. Lancet. 1983;1(8331):958-960.

164. Kienlen Campard P, Crochemore C, Rene F, et al. PACAP type I receptor activation promotes cerebellar neuron survival through the cAMP/PKA signaling pathway. DNA Cell Biol. 1997;16(3):323-333.

165. D'Mello SR, Galli C, Ciotti T, et al. Induction of apoptosis in cerebella granule neurons by low potassium: inhibition of death by insulin-like growth factor I and cAMP. Proc Natl Acad Sci USA. 1993;90(23):10989-10993.

166. Hanson MG Jr, Shen S, Wiemelt AP, et al. Cyclic AMP elevation is sufficient to promote the survival of spinal motor neurons in vitro. $J$ Neurosci. 1998;18(18):7361-7371.

167. Miller TM, Tansey MG, Johnson EM Jr, et al. Inhibition of phosphatidylinositol 3-kinase activity blocks depolarization and insulinlike growth factor I-mediated survival of cerebllar granule cells. $J$ Biol Chem. 1997;272(15):9847-9853.

168. RydelRE, Greene LA. cAMP analogs promote survival and neurite outgrowth in cultures of rat sympathetic and sensory neurons independently of nerve growth factor. Proc Natl Acad Sci USA. 1988;85(4):1257-1261.

169. Villalba M, Bockaert J, Journot L. Pituitary adenylate cyclase activating polypeptide (PACAP-38) protects cerebellar granule neurons from apoptosis by activating the mitogen-activated protein kinase (MAP kinase) pathway. J Neurosci. 1997;17(1):83-90.

170. Plyte SE, Hughes K, Nikolakaki E, et al. Glycogen synthase kinase-3: functions in oncogenesis and development. Biochim Biophys Acta. 1992;1114(2-3):147-162.

171. KewJN, Smith DW, Sofroniew MW. Nerve growth factor withdrawal induces the apoptotic death of developing septal cholinergic neurons in vitro: protection by cyclic AMP analogue and high potassium. Neuroscience. 1996;70(2):329-339.

172. Anderson CN, Tolkovsky AM. A role for MAPK/ERK insympathetic neuron survival: protection against a p53-dependent, JNK-independent induction of apoptosis by cytosine arabinoside. $J$ Neurosci. 1999;19(2):664-673.

173. Crowder RJ, Freeman RS. The survival of sympathetic neurons promoted by potassium depolarization, but not cAMP, requires phosphatidylinositol 3-kinase and Akt. J Neurochem. 1999;73(2):466-475.

174. Virdee K, Tolkovsky AM. Activation of p44 and p42 MAP kinases is not essential for the survival of rat sympathetic neurons. Eur J Neurosci. 1995;7(10):2159-2169.
175. Vetrugno M, Uva MG, Russo V, et al. Oral administration of forskolin and rutin contributes to intraocular pressure control in primary open angle glaucoma patients under maximum tolerated medical therapy. $J$ Ocular Pharmacol and Therapeutics. 2012;28(5):536-542.

176. Sisto D, Lavermicocca N, Errico D, et al. Oral Administration of Forskolin and Rutin Contributes to Reduce Intraocular Pressure and Improve PERG (Pattern Electroretinogram) Amplitude in Glaucomatous Patients. JSM Biotechnol Bioeng. 2013;2(1):1036.

177. Shen Y, He P, Fan YY, et al. Carnosine protects against permanent cerebral ischemia in histidine decarboxylase knockout mice by reducing glutamate excitotoxicity. Free Radic Biol Med. 2010;48(5):727-735.

178. Fu Q, Dai H, Hu W, et al. Carnosine protects against Abeta42-induced neurotoxicity in differentiated rat PC12 cells. Cell Mol Neurobiol. 2008;28(2):307-316.

179. Preston JE, Hipkiss AR, Himsworth DT, et al. Toxic effects of betaamyloid(25-35) on immortalised rat brain endothelial cell: protection by carnosine, homocarnosine and beta-alanine. Neurosci Lett. 1998;242(2):105-108.

180. Corona C, Frazzini V, Silvestri E, et al. Effects of dietary supplementation of carnosine on mitochondrial dysfunction, amyloid pathology, and cognitive deficits in 3xTg-AD mice. PLoS One. 2011;6(3):e17971.

181. Oddo S, Caccamo A, Shepherd JD, et al. Tripletransgenic model of Alzheimer's disease with plaques and tangles: intracellular Abeta and synaptic dysfunction. Neuron. 2003;39(3):409-421.

182. Ji D, Kamalden TA, Del Olmo-Aguado S, et al. Light- and sodium azideinduced death of RGC-5 cells in culture occurs via different mechanisms. Apoptosis. 2011;16(4):425-437.

183. Moxon-Lester L, Takamoto K, Colditz PB, et al. S-adenosyl-L-methionine restores photoreceptor function following acute retinal ischemia. Vis Neurosci. 2009;26(5-6):429-441.

184. Linnebank M, Popp J, Smulders Y, et al. S-adenosylmethionine is decreased in the cerebrospinal fluid of patients with Alzheimer's disease. Neurodegener Dis. 2010;7(6):373-378.

185. Majumdar A, Cruz D, Asamoah N, et al. Activation of microglia acidifies lysosomes and leads to degradation of Alzheimer amyloid fibrils. Mol Biol Cell. 2007;18(4):1490-1496.

186. Seamon KB, Daly JW. Forskolin: A unique diterpene activator of cyclic AMP generating systems. J Cyclic Nucleotide Res. 1981;7(4):201-224. 